\title{
Neuron Specific Enolase Measurement
}

National Cancer Institute

\section{Source}

National Cancer Institute. Neuron Specific Enolase Measurement. NCI Thesaurus. Code C116205.

The determination of the amount of neuron specific enolase present in a sample. 